\title{
Performance Analysis of 10G/2.5G Asymmetric XGPON Transmission using RZ and NRZ Data Formats
}

\author{
${ }^{1}$ Amandeep Kaur \\ ${ }^{2}$ M.L.Singh \\ ${ }^{3}$ Anu Sheetal \\ ${ }^{1,2}$ Department of Electronics Technology, Guru Nanak Dev University, Amritsar, India-143005 \\ ${ }^{3}$ Department of Electronics and Communication, Guru Nanak Dev University, Regional campus, \\ Gurdaspur-143521
}

\begin{abstract}
In this paper, a fiber optic communication system has been employed using 10G/2.5G asymmetric XGPON architecture. In this system bidirectional optical fiber has been employed for upstream and downstream data transmission. The system performance has been investigated for non-return-to-zero (NRZ) and return-to-zero (RZ) data formats by varying the length of the fiber for co-existed GPON and XG-PON system. The results have been compared for NRZ and RZ formats for upstream and downstream data in terms of $\mathrm{Q}$ value and eye opening. It has been observed that RZ modulation format is superior compared to conventional NRZ modulation.
\end{abstract}

Keywords: XG-PON, GPON, data formats, NRZ, RZ

\section{INTRODUCTION}

Increasing demand of bandwidth due to rapid growth of P2P, HDTV, 3DTV and Cloud Computing creates new challenges to bandwidth deployment and operation. Passive optical networks (PONs) are the most important class of fiber access network in the world today. A PON is a point-to-multipoint optical network, where an Optical Line Terminal (OLT) at the Central Office (CO) is connected to many Optical Network Units (ONUs) at remote nodes through one or multiple 1: $\mathrm{N}$ optical splitters. The network between the OLT and the ONU is passive i.e., it does not require any power supply [1][2]. The direction of PON evolution is a key issue for the telecom industry. As the users' demands for bandwidth are ever increasing, next generation passive optical networks (NG-PONs) are being standardized by ITU-T and IEEE standards. Furthermore, the future access network requires increased bit rates up to $10 \mathrm{~Gb} / \mathrm{s}$ to satisfy the increasing traffic demands. Two stages of NGPON evolution have been planned by Full Service Access Network (FSAN) group: NG-PON1 and NG-PON2. NG-PON1 extended from the existing G-PON standards and compatible with the current optical distribution network (ODN). NG-PON2 is a long-term solution with an entirely new optical network type. In contrast, NG-PON1 is a mid-term upgrade from the GPON system with backward compatibility to the existing fiber deployments. NG-PON1 is also called XG-PON1. XG-PON1 features asymmetric transmission of $10 \mathrm{~Gb} / \mathrm{s}$ downstream and $2.5 \mathrm{~Gb} / \mathrm{s}$ upstream [3]. $10 \mathrm{~Gb} / \mathrm{s}$ is selected for downstream transmission, as a cost effective way to transmit large amounts of data. In the upstream direction, $10 \mathrm{~Gb} / \mathrm{s}$ burst mode time division multiple access (TDMA) is a challenging issue for its high data rate. The difficulty of designing and manufacturing such components prohibits using $10 \mathrm{~Gb} / \mathrm{s}$ in the upstream direction. Thus $2.5 \mathrm{~Gb} / \mathrm{s}$ is selected as an economical and practical upgrade solution [4].
XG-PON2 is a symmetric system with the bidirectional rate of $10 \mathrm{~Gb} / \mathrm{s}$. To ensure the smooth upgrade from GPON to XGPON coexistence of both systems is mandatory and it can be done with wavelength division multiplexing [5]. A coexisting XG-PON and GPON can be very cost effective as the system shares common infrastructure and reduces the number of central offices $(\mathrm{CO})$.

Bostjan et al. [6] analyzed the future trends in the development next-generation Passive Optical Network (NG-PON). As an enhancement to Gigabit-capable Passive Optical Network (GPON), Ten-Gigabit-Capable Passive Optical Networks (XGPON1) inherited the framing and management from GPON. XG-PON1 provides full-service operations via $4 \mathrm{x}$ higher rate and $2 \mathrm{x}$ larger split to support a PON network structure. All future strategies for NG-PON evolution are expected to deploy wavelength division multiplexing (WDM) which satisfies demands for increasing traffic and higher bandwidths.

Benyuan et al. [7] described the coexistence of 10G-PON and GPON compatible reach extender using Raman amplifications and low cost SOA as power boosters to improve the loss budgets for both GPON and XG-PON. By mean of this operation authors demonstrated the coexistence of XG-PON and GPON bi-directional transmission over $50-\mathrm{km}$ of All Wave fiber with entirely passive fiber components.

Petar et al. [8] simulated model of coexisting GPON and NGPON1 (10G-PON) systems using NRZ format, which has been developed for the analysis of feasibility and implementation issues of this coexistence. The aim was to analyse the impact of the most important parameters of the components that are needed for new network elements, on the performance of these coexistent networks.

The non-return-to-zero (NRZ) has been the most dominant modulation format as it is not sensitive to laser phase noise, requires a relatively low electrical bandwidth for transmitter and receivers as compared to $\mathrm{RZ}$ and the simplest configuration of transmitter and receiver. The NRZ pulses have a narrow optical spectrum and this reduced spectrum width improves the dispersion tolerance but it has the effect of intersymbol interference (ISI). The RZ pulse occupies just a part of the bit slot, so it has a duty cycle smaller than 1 and a broad spectrum. The RZ pulse shape enables an increased robustness to fiber nonlinear effects [9].

It has been examined that the feasibility of RZ format in XGPON system is not available as such in the literature and thus is explored here to investigate the performance of $10 \mathrm{G} / 2.5 \mathrm{G}$ asymmetric XG-PON system for NRZ and RZ data formats. Here, in section 2, the system description and modeling has 
been described. In section 3, the results of the system using NRZ and RZ formats for upstream and downstream data transmission have been compared by varying length and finally in section 4 , conclusions are made.

\section{SYSTEM DESCRIPTION}

The schematic of optical communication system for coexisted XG-PON and GPON is shown in Fig 1. A Distributed Feedback laser diode with power $=3 \mathrm{dBm}$ in NRZ/RZ format at $1490 \mathrm{~nm}$ is used as GPON downstream transmitter. An electroabsorption modulated laser $(E M L)$ with power $=0 \mathrm{dBm}$ in NRZ/RZ format at $1577 \mathrm{~nm}$ is used as XG-PON downstream transmitter. This EML at 1577 is designed for $10 \mathrm{~Gb} / \mathrm{s}$ transmission. As specific demands of the optical- transceiver in market and industry, the FSAN/ITU-T group selected the bandwidth between $1575 \mathrm{~nm}$ and $1580 \mathrm{~nm}$ for the downstream and $1260 \mathrm{~nm}$ to $1280 \mathrm{~nm}$ for the upstream transmission of XGPON. The downstream window is only $5 \mathrm{~nm}$ wide. To operate normally, such a narrow band uses cooled laser sources to stabilize the wavelength. Such special sources have very high costs. The upstream window being $20 \mathrm{~nm}$ wide, uncooled laser sources can be used and the ONU optics costs decreased [10]. Two low cost SOAs are integrated with downstream transmitter to boost both $1577 \mathrm{~nm}$ and $1490 \mathrm{~nm}$ signal powers before launching into feeder fiber to accommodate high loss budget for long reach. The booster SOAs for $1490 \mathrm{nmand} 1577 \mathrm{~nm}$ downstream has $15 \mathrm{dBm}$ and $16 \mathrm{dBm}$ saturated power respectively, and these SOAs are operated in a linear regime to reduce pattern dependent distortion due to gain dynamics of the SOA. Two pumps at wavelength $1206 \mathrm{~nm}$ with power $=850 \mathrm{~mW}$ and $1240 \mathrm{~nm}$ with power $=520 \mathrm{~mW}$ are used to be coupled into the bidirectional feeder fiber to provide distributed Raman gains for the XG-
PON upstream signal band $(1260-1280 \mathrm{~nm})$ and GPON upstream signal band $(1300-1320 \mathrm{~nm})$ respectively. A WDM combiner is employed to combine the XG-PON /GPON downstream signals and Pump lasers, and it also separates XGPON/GPON upstream signals. The passband of the WDM combiner is designed to ensure compatibility with the wavelength plan specifications for XG-PON and GPON signals as defined in ITU-T standards [11].The WDM combiner is able to filter out undesired Raman ASE noise outside of the upstream signal bands to improve the transmission performance. The bidirectional optical fiber with reference wavelength $=1322 \mathrm{~nm}$ lies between $1300 \mathrm{~nm}$ and $1324 \mathrm{~nm}$ which is zero dispersion wavelength, having Dispersion $=0 \mathrm{ps} / \mathrm{nm} / \mathrm{km}$ and dispersion slope $=0.086 \mathrm{ps} / \mathrm{nm}^{2} / \mathrm{km}$. The optical fiber taking into account attenuation and fiber non-linearity effect such as Self-phase Modulation (SPM) and Cross-phase Modulation(XPM). A cyclic 1:2 WDM Mux/Demux is employed with combination of 1:64 and 1:32 optical splitters for GPON and XG-PON respectively in Remote node (RN). The ONU consist of BPF GPON downstream at frequency $1490 \mathrm{~nm}$ having bandwidth $=10 \mathrm{~nm}$ and $\mathrm{BPF}$ XG-PON downstream at frequency $1577 \mathrm{~nm}$ having bandwidth $=10 \mathrm{~nm}$. The signal is detected by Avalanche Photo detector (APD) receivers at $1490 \mathrm{~nm}$ and $1577 \mathrm{~nm}$. It is passed through two low pass Bessel Filters with $3 \mathrm{~dB}$ cut-off frequency $=0.75 \times$ Bitrate $/ 4$ and $3 \mathrm{~dB}$ cut-off frequency $=0.75 \times$ Bitrate respectively. Thereafter, $3 \mathrm{R}$ regenerator is used to regenerate the electrical signal that can be connected directly to the BER analyzer, which is used as a visualizer to generate graphs and results such as eye diagram, BER, Q value, eye opening etc.

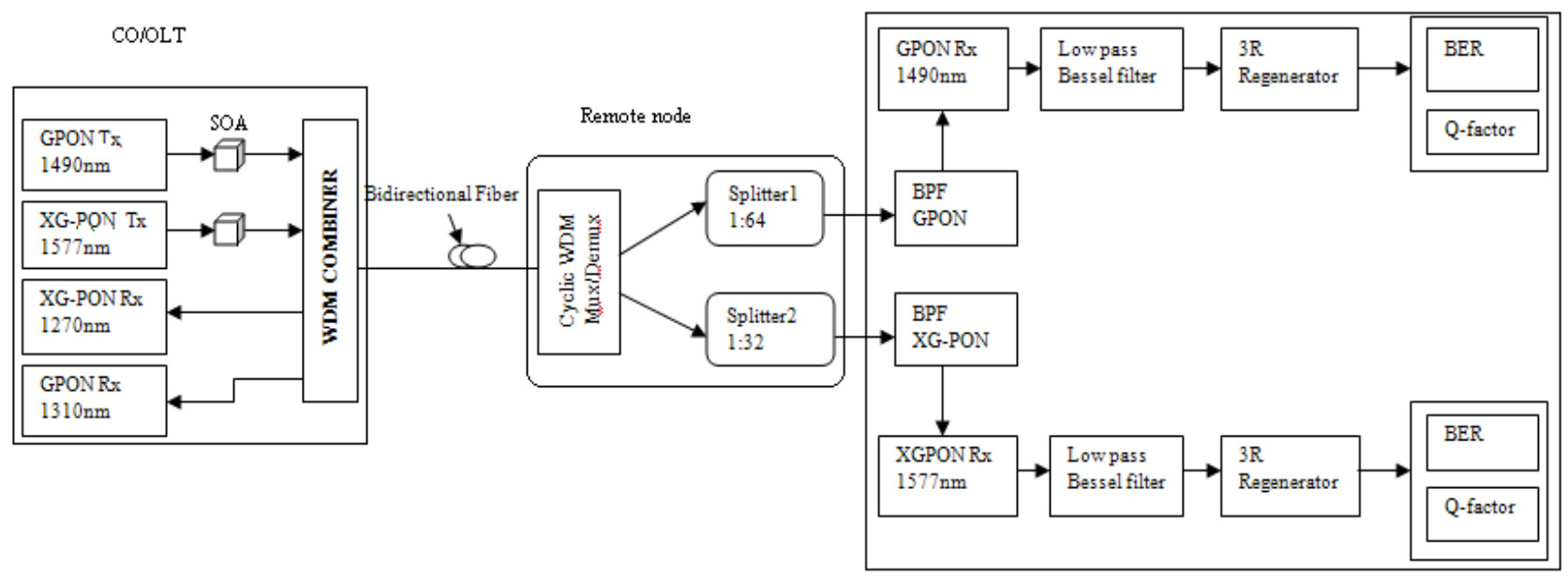

Fig 1. Schematic of System Setup

\section{RESULTS AND DISCUSSION}

To estimate the performance, the BER and Q value $[\mathrm{dB}]$ from the eye diagrams of electrical scope have been considered for GPON and XG-PON. Fig 2(a) \& (b) shows the graphical representation of $\mathrm{Q}$ value as a function of Length for NRZ and $\mathrm{RZ}$ (with duty cycle $=0.6$ and 0.8 ) data formats for GPON and XG-PON respectively for downstream data transmission. In fig2(a), comparing the results of NRZ and RZ transmission, it turns out that RZ data format performs better than NRZ as RZ has improved receiver system and launches average power into the fiber. The presence of non-linearities in bidirectional optical fiber such as SPM and XPM depends on peak power and interaction time. However, RZ pulses have larger peak power and as such more susceptible to SPM and XPM. In the presence of SPM, these pulses can undergo compression and performs better than NRZ pulses. The Q-factor obtained is $27.48 \mathrm{~dB}$ and $12.59 \mathrm{~dB}$ at a distance of $50 \mathrm{~km}$ and $70 \mathrm{~km}$ respectively in downstream transmission for RZ (0.6) format. After $70 \mathrm{~km}$, the system gives same performance for NRZ, RZ (0.8) and RZ (0.6) as data formats have no prominent impact at higher length in case of GPON system. For GPON, the faithful transmission distance is up to $85 \mathrm{~km}$ in $\mathrm{RZ}$ (0.6) format.

In fig 2(b), RZ is again better than NRZ format for XGPON system. The Q-factor obtained is $9.68 \mathrm{~dB}$ and $8.57 \mathrm{~dB}$ at a distance of $50 \mathrm{~km}$ and $70 \mathrm{~km}$ respectively for XGPON in downstream transmission for RZ (0.6) format. It is clear from figures that $\mathrm{Q}$-value decreases with increase in length of fiber 
due to fiber non-linearities and attenuation effect. For XGPON, the faithful transmission distance is up to $85 \mathrm{~km}$ in $\mathrm{RZ}(0.6)$ format for downstream transmission, where the minimum acceptable $\mathrm{Q}$ factor is $6.0 \mathrm{~dB}$ at BER $10^{-9}$ for faithful transmission.

RZ modulation has become a popular solution for $10 \mathrm{~Gb} / \mathrm{s}$ systems because it has average peak power, a higher signal-tonoise ratio, and lower bit error rate that NRZ encoding. It also offers better immunity to fiber nonlinear effects. RZ modulation is found to be less susceptible to inter-symbol interference (ISI), and typically achieves better performance compared to NRZ

Fig 3(a) \& (b) shows the graphical representation of Q value as a function of Length for NRZ and RZ (with duty cycle $=0.6$ and 0.8 ) data formats for GPON and XG-PON respectively for upstream data. In fig 3(a), the graph clearly shows that RZ format is better option for this system for upstream data transmission. The upstream faithful transmission distance could be carried out greater than $150 \mathrm{~km}$ for GPON in RZ (0.6) format. In fig 3(b), the graph clearly shows the faithful upstream transmission distance could be carried out up to $100 \mathrm{~km}$ for XGPON in RZ (0.6) format, where the minimum required value for $\mathrm{Q}$ is $6.0 \mathrm{~dB}$ at BER $10^{-9}$.

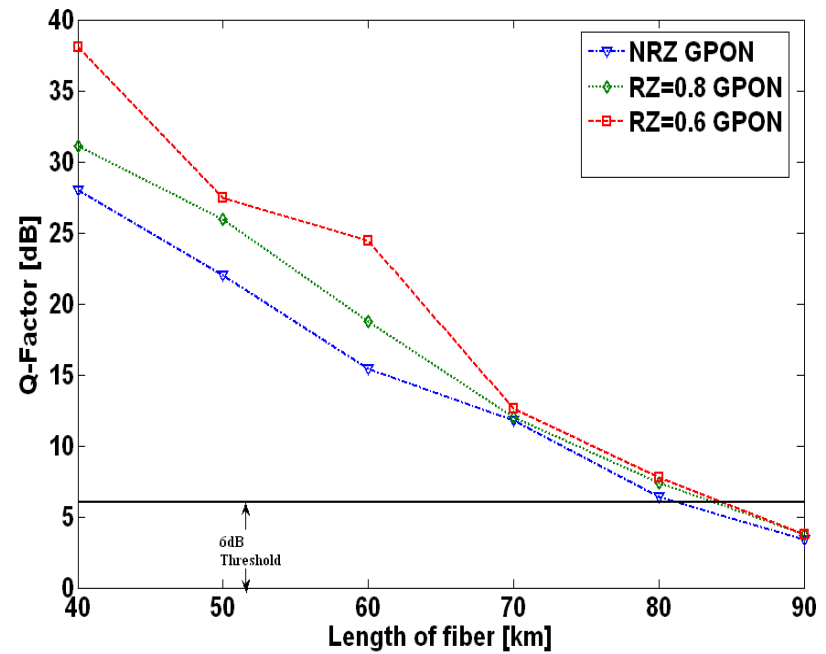

Fig 2(a) Length Vs Q-Factor of GPON for NRZ and RZ formats for downstream transmission

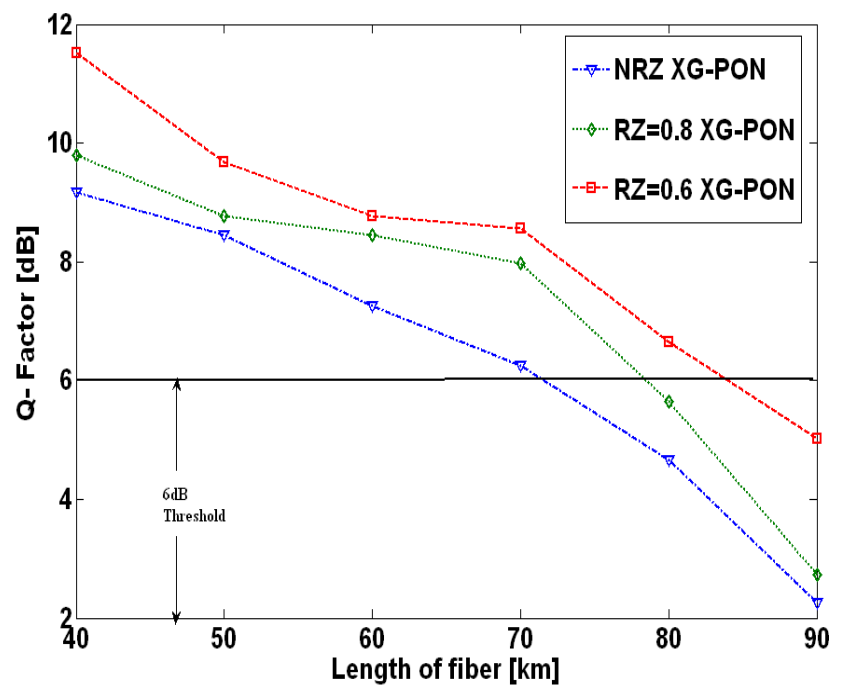

Fig 2(b) Length Vs Q-Factor of XGPON for NRZ and RZ formats for downstream transmission

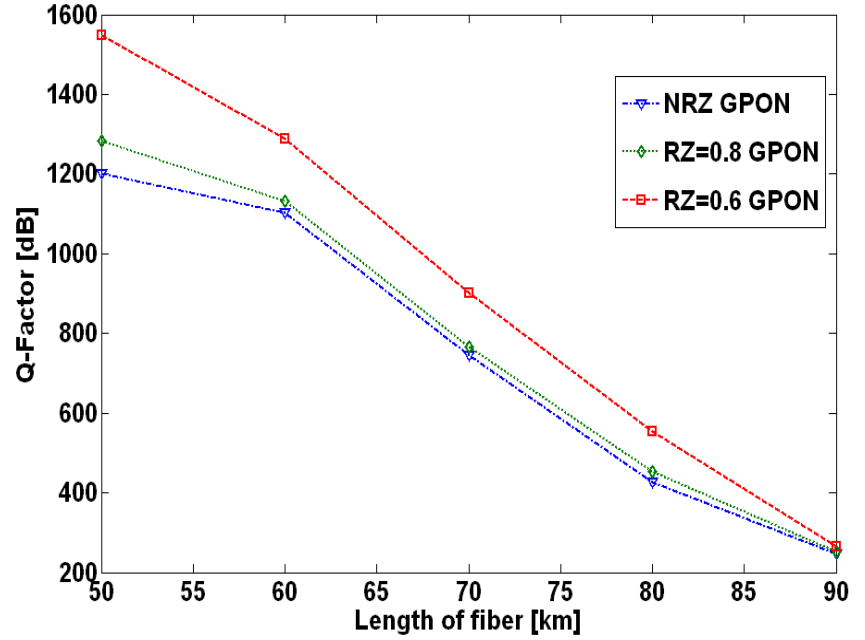

Fig 3(a) Length Vs Q-Factor of GPON for NRZ and RZ formats for upstream transmission

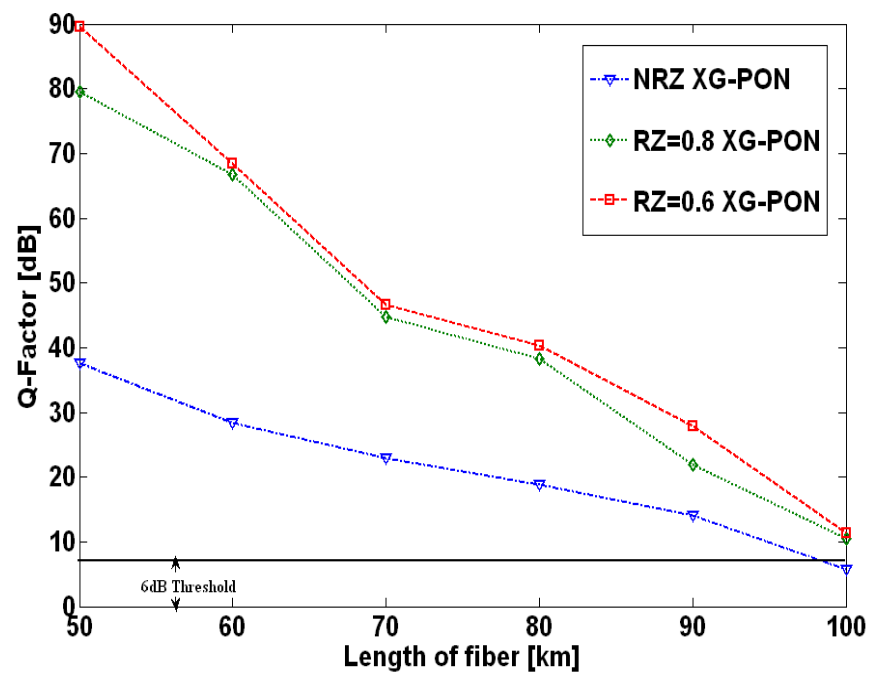

Fig 3(b) Length Vs Q-Factor of GPON for NRZ and RZ formats for upstream transmission

Table 1 gives faithful transmission distance for varying modulation formats. The Q-value obtained is $265.81 \mathrm{~dB}$ and $27.89 \mathrm{~dB}$ at a distance of $90 \mathrm{~km}$ for GPON and XGPON respectively in upstream transmission for RZ (0.6) format. The minimum required Q-value for faithful transmission is $6.0 \mathrm{~dB}$ at BER $10^{-9}$. These values shows that the performance of $\mathrm{RZ}=0.6$ is much better than NRZ and $\mathrm{RZ}=0.8$ for both upstream and downstream transmission. Fig $4 \& 5$ shows the eye diagrams for GPON and XG-PON in RZ (0.6) format at $70 \mathrm{~km}$ for upstream and downstream respectively. These results further endorse the results of the earlier discussion

Table1. Faithful transmission distance for varying modulation formats

\begin{tabular}{|c|c|c|c|c|}
\hline & \multicolumn{2}{|c|}{ GPON } & \multicolumn{2}{|c|}{ XG-PON } \\
\hline & DS & US & DS & US \\
\hline RZ(0.6) & $>80 \mathrm{Km}$ & $\begin{array}{l}\text { Up to } \\
150 \mathrm{~km}\end{array}$ & $\begin{array}{c}\text { Up to } 85 \\
\text { km }\end{array}$ & $>100 \mathrm{~km}$ \\
\hline RZ(0.8) & $\geq 80 \mathrm{~km}$ & $\geq 120 \mathrm{~km}$ & $\begin{array}{l}\text { Up to } \\
80 \mathrm{~km}\end{array}$ & $\geq 100 \mathrm{~km}$ \\
\hline NRZ & $\begin{array}{l}\text { Up to } \\
80 \mathrm{~km}\end{array}$ & $\begin{array}{l}\text { Up to } \\
120 \mathrm{~km}\end{array}$ & $\begin{array}{l}\text { Up to } \\
70 \mathrm{~km}\end{array}$ & $\begin{array}{l}\text { Up to } \\
100 \mathrm{~km}\end{array}$ \\
\hline
\end{tabular}




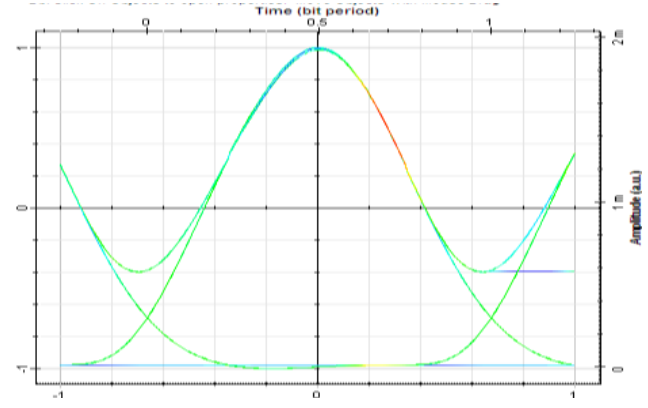

(a)

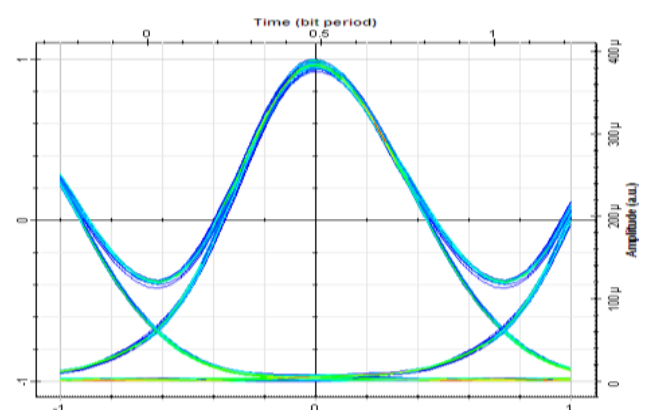

(b)

Fig 4 Eye Diagram for (a) GPON and (b) XGPON respectively at distance of $70 \mathrm{~km}$ in $\mathrm{RZ}(0.6)$ data formats for upstream transmission

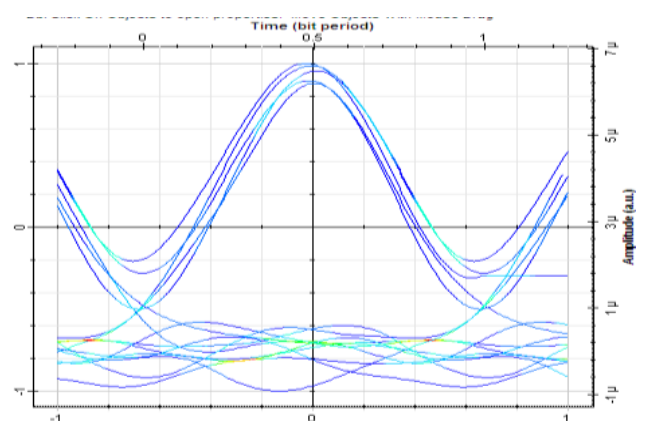

(a)

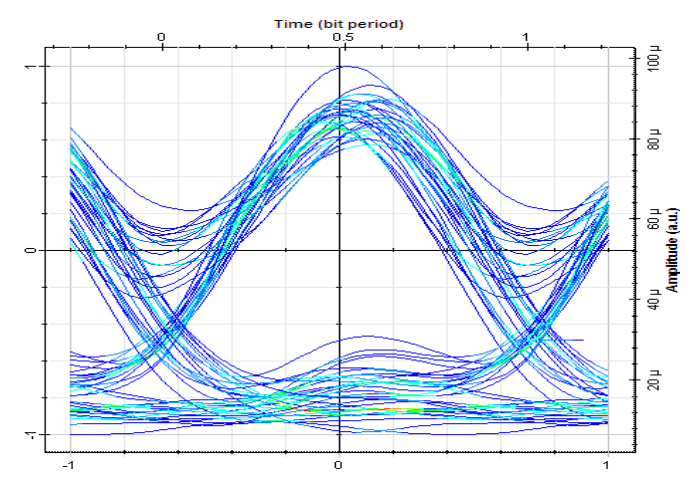

(b)

Fig 5 Eye Diagram for (a) GPON and (b) XGPON respectively at distance of $70 \mathrm{~km}$ in $\mathrm{RZ}(0.6)$ data formats for downstream transmission

\section{CONCLUSION}

The potential of NRZ and RZ signal transmission for Coexisted GPON and XG-PON system has been analyzed over a transmission distance of $80 \mathrm{~km}$.It is found that the faithful transmission distance covered by XG-PON is greater than $80 \mathrm{~km}$ for both upstream and downstream transmission in RZ format. It is concluded that for this co-existed system the RZ modulation format is superior to the conventional NRZ modulation scheme as it offers better immunity to fiber nonlinearities. Further, it is found that the performance of XG-PON deteriorates due to greater non- linear effects at higher Bit rate.

\section{REFERENCES}

[1] Rajniti, Anita Suman, Anu Sheetal, Parveen " Comparison of RZ and NRZ data formats for $2.5 \mathrm{~Gb} / \mathrm{s}$ bidirectional WDM/TDM-PON using narrowband AWG" International Journal of VLSI and Signal Processing Applications, Vol. 1, Issue 2 , May 2011.

[2] Wang Xinsheng, "Insights into Next Generation PON Evolution", ZTE Technologies, VOL. 14 NO. 4 ISSUE 141, 2012,pp-12-15.

[3] ITU-T Series Recommendation G.987.2,(2010).

[4] Yuanqiu Luo, Frank Effenberger, and Bo Gao "Transmission Convergence Layer Framing in XG-PON1" Huawei Technologies USA.

[5] Ning Cheng, Zhenxing Liao, Shuang Liu, and Frank Effenberger "Gain-Clamped Semiconductor Optical Amplifiers for Reach Extension of Coexisted GPON and XG-PON", NTuD7. (2011).

[6] Bostjan Batagelj, Vesna Erzen, Vitalii Bagan, Yury Ignatov "Optical Access Network Migration from GPON to XG-PON" in ACCESS 2012 : The Third International Conference on Access Networks.

[7] Benyuan Zhu, David Au, Faroog Khan, and Yaowen Li "Coexistence of 10G-PON and GPON Reach Extension to 50-km with Entirely Passive Fiber Plant" ECOC 2011 OSA ,Th.13.B.5.(2011)

[8] Marija D. Mraković and Petar S. Matavulj "Analysis of Coexisting GPON and NG-PON1 (10G-PON) Systems" Telfor Journal, Vol. 3, No. 1, 2011.

[9] Rahul Chhilar, Jitender Khurana, Shubham Gandhi "Modulation formats in optical communication system" International Journal of Computational Engineering \& Management, Vol. 13, July 2011

[10] Vesna Eržen, Boštjan Batagelj "NG-PON1: technology presentation, implementation in practice and coexistence with the GPON system" ELEKTROTEHNIŠKI VESTNIK 79(3): 117-122, 2012.

[11] ITU-T Series Recommendation G.984.5,(2008). 